\title{
Inflammatory bowel disease and predisposition to osteopenia
}

\author{
F J Cowan, J T Warner, F D J Dunstan, W D Evans, J W Gregory, H R Jenkins
}

\begin{abstract}
The prevalence of osteopenia in children with inflammatory bowel disease (IBD) is unknown. The effect of nutritional state, disease activity, and steroid therapy on bone mineral content (BMC) of whole body, lumbar spine, and left femoral neck measured by dual energy $x$ ray absorptiometry in 32 children with IBD was assessed by comparison with 58 healthy local school children. Using the control data, a predicted BMC was calculated taking into account bone area, age, height, weight, and pubertal stage. The measured BMC in children with IBD was expressed as a percentage of this predicted value $(\%$ BMC). Mean (SD) \% BMC was significantly reduced for the whole body and left femoral neck in the children with IBD (97.0 (4.5)\% and $93.1(12.0) \%$ respectively, p<0.05). Of the children with IBD, $41 \%$ had a \% BMC less than 1 SD below the mean for the whole body and $47 \%$ at the femoral neck. Reduction in \% BMC was associated with steroid usage but not with the magnitude of steroid dose, disease activity, or biochemical markers of bone metabolism. In conclusion, osteopenia is relatively common in childhood IBD and may be partly related to the previous use of steroids.

(Arch Dis Child 1997;76:325-329)
\end{abstract}

Keywords: osteopenia; inflammatory bowel disease; bone mineral content

Osteopenia is well recognised in adults with inflammatory bowel disease (IBD). ${ }^{1}$ The pathophysiology is unclear but is probably a combination of a number of inter-related factors. The inflammatory process itself, with the release of cytokines, may have a direct effect on bone mineralisation, ${ }^{2}$ and episodes of malabsorption and malnutrition along with periods of physical inactivity during acute relapse together may inhibit bone formation. ${ }^{3}$ IBD often necessitates treatment with relatively high doses of steroids for prolonged periods of time. Steroids are known to affect bone mineralisation by a direct inhibitory action on osteoblast activity, reduction of intestinal absorption of calcium, stimulation of parathyroid hormone release, and by adverse effects on growth hormone action. ${ }^{4}$ Steroids have also been shown to reduce gonadal hormone production. ${ }^{5}$ Future fracture risk is closely related to peak bone mass which is achieved soon after the end of puberty. ${ }^{6}$ Children with
IBD have a frequently delayed and truncated pubertal growth spurt which may have adverse effects on the achievement of peak bone mass. ${ }^{7}$

Bone mineral status can be assessed by means of dual energy $x$ ray absorptiometry (DXA). The case has been reported of a child who, soon after the diagnosis of Crohn's disease, suffered several vertebral fractures secondary to severe osteopenia demonstrated on DXA scan. ${ }^{8}$ The incidence and wider prevalence of osteopenia in childhood IBD is not known. In the study reported here, bone mineral content (BMC) of the whole body, lumbar spine, and left femoral neck was measured by DXA in children with IBD and compared with that in a healthy local British control population. The effect of nutritional status, disease activity, and steroid therapy on the BMC of children with IBD was also assessed.

\section{Subjects and methods}

SUBJECTS

All children with IBD attending the gastroenterology clinic at the University Hospital of Wales participated in the study. Twenty one (10 boys) had Crohn's disease and 11 (eight boys) ulcerative colitis. Fifty eight (29 male) healthy schoolchildren from the South Wales area were recruited as control subjects. This control group comprised 31 (17 male) siblings of children participating in another study in the department and 27 (12 male) relatives of staff within our department and volunteers from a local school. The control group was chosen to provide data from normal healthy children over as wide an age range as possible. No attempt was made to match the control children individually with the children with IBD because of the shorter stature in the latter. Informed consent was obtained from the parents and children. The study was approved by the South Glamorgan Health Authority research ethics committee.

\section{METHODS}

Auxology

Height was measured on a wall mounted Harpenden stadiometer (Holtain Ltd, Crymych, Dyfed) and weight on an Avery beam balance (Avery Ltd, Birmingham) by two trained observers. Body mass index was calculated from weight $(\mathrm{kg}) /$ height $^{2}\left(\mathrm{~m}^{2}\right)$. The measurements were expressed as SD scores using the 1990 growth standards for British children. $^{910}$ Puberty was assessed by the method of Tanner. ${ }^{11}$ 
Table 1 Calculation of steroid score

\begin{tabular}{llll}
\hline Score & $\begin{array}{l}\text { (A) Daily dosage } \\
\text { (mg/kg) }\end{array}$ & $\begin{array}{l}\text { (B) Duration } \\
\text { (years) }\end{array}$ & (C) Mode \\
\hline 0 & 0 & 0 & Never \\
1 & $<0.5$ & $<0.5$ & Intermittently \\
2 & $0.5-1.0$ & $0.5-1.0$ & Continuous \\
3 & $1.1-1.5$ & $1.1-2.0$ & \\
4 & $1.6-2.0$ & $2.1-3.0$ & \\
5 & $>2$ & $>3$ &
\end{tabular}

Total steroid score $=\mathrm{A} \times \mathrm{B} \times \mathrm{C}$.

\section{Body composition}

Body composition, as a marker of nutritional state, was assessed by skinfold thickness and DXA. Skinfold thickness was measured at the biceps, triceps, subscapular, and suprailiac sites and fat-free mass and percentage fat ( $\%$ fat) calculated using the equations of Brook for prepubertal children, ${ }^{12}$ Durnin and Rahaman for children in puberty ${ }^{13}$ and the equation of Siri. ${ }^{14}$

DXA measurements of fat-free mass and \% fat were performed on a QDR 1000/W scanner (Hologic Inc, Waltham, MA, USA). ${ }^{15}$

\section{Bone mineralisation}

DXA measurements of BMC and bone area (BA) were taken for the whole skeleton, lumbar spine (L1-L4) and left femoral neck using the Hologic QDR 1000/W bone densitometer. Conventionally, bone mineralisation data have been expressed as an areal bone mineral density (BMD) - that is, $\mathrm{BMC} / \mathrm{BA}$; however, this fails to correct $\mathrm{BMC}$ for $\mathrm{BA}$ as both remain correlated with BMD. Furthermore BMD fails to remove the correlation of BMC with age, body size,$^{16}$ and pubertal stage. Therefore predictive equations were produced for BMC based on the control population, using multiple regression analysis, with $\mathrm{BMC}$ as the dependent variable and $\mathrm{BA}$, age, height, weight, pubertal stage, and gender as the independent variables. Independent variables were selected using a backward stepwise procedure such that all remaining variables in the final predictive formula for BMC were statistically significant $(\mathrm{p}<0.05)$. All continuous variables were converted to natural logarithms so as to linearise their relationship with BMC. The measured $\mathrm{BMC}$ was expressed as a percentage of the predicted value (\% BMC), which allows comparison of values in subjects with a wide range of body size and age with the control population.

Biochemical measures of bone metabolism Serum concentrations of calcium, phosphate, 25-hydroxycholecalciferol, and parathyroid hormone were measured as indices of calcium homoeostasis. The serum concentration of

Table 2 Auxology and body composition measurements; values are mean (SD)

\begin{tabular}{lll}
\hline & Patients with IBD & Controls \\
\hline Age (years) & $14.2(2.8)$ & $11.9(3.0)$ \\
Height SD score & $-0.68(1.1)^{\star}$ & $0.24(0.9)$ \\
Weight SD score & $-0.43(1.3)^{\star}$ & $0.47(1.0)$ \\
Body mass index SD score & $-0.15(1.3)$ & $0.24(1.1)$ \\
\% Fat skinfolds (boys) & $23.0(8.0)$ & $23.2(1.5)$ \\
\% Fat DXA (boys) & $19.1(5.6)$ & $19.6(6.5)$ \\
\% Fat skinfolds (girls) & $31.7(5.7)$ & $27.8(1.0)$ \\
\% Fat DXA (girls) & $27.2(4.7)$ & $24.4(6.9)$ \\
\hline
\end{tabular}

$\star \mathrm{p}<0.005$ alkaline phosphatase was measured as a marker of bone formation, and fasting spot urine hydroxyproline/creatinine ratio was measured as a marker of bone resorption.

Disease activity

Disease activity was measured at the time of participation in the study and by retrospective case note analysis from clinic visits over the preceding year. Disease activity for Crohn's disease was measured by a modified Harvey Bradshaw index. ${ }^{17}$ This index is based on five clinical variables (general well being, presence and severity of abdominal pain, number of liquid stools per day, presence of an abdominal mass, and the presence of complications), which produce a composite score between 0 and 20. Disease activity in ulcerative colitis was measured by the criteria of Truelove and Witts, ${ }^{18}$ which classifies activity in terms of clinical severity (mild, moderate, and severe). To allow for statistical comparisons with the group of children with Crohn's disease, a numerical score was then applied to the severity classifications (mild, 2; moderate, 6; severe, 10).

\section{Steroid usage}

The duration and dosage of steroid treatment was recorded. The magnitude of steroid treatment was calculated using a modification of the method described by Motil et al. ${ }^{19}$ This is based on a composite score of daily dosage in $\mathrm{mg} / \mathrm{kg}$, duration of treatment, and mode (whether given continuously or intermittently) (table 1).

\section{STATISTICAL ANALYSIS}

Group means were compared using independent $t$ tests, allowing mean differences and 95\% confidence intervals to be calculated. The different steroid groups were compared using one way analysis of variance (ANOVA). Where the $F$ ratio was significant $(p<0.05)$ Tukey's post hoc multiple comparison test was applied to compare individual groups with each other. The distribution of \% BMC was tested for normality using the Kolmogorov-Smirnov test.

\section{Results}

AUXOLOGY AND BODY COMPOSITION

Although the control group was slightly younger, there was no significant difference between the ages of the patients and the controls (table 2). The children with IBD were significantly shorter and lighter than the controls $(p<0.005)$, although there were no significant differences between patients and controls in any of the measures of body composition. However, as might be expected, girls had a higher \% body fat than boys in both groups $(\mathrm{p}<0.001)$. The two groups were at similar stages of puberty (median stage 3 ).

\section{BONE MINERAL CONTENT}

The mean \% BMC for each site for the controls is close to $100 \%$, which is to be expected since the predicted $\mathrm{BMC}$ is derived from the control population (table 3). \% BMC was normally distributed at each site (Kolmogorov-Smirnov test, $\mathrm{p}>0.20$ ), and the SD at each site then 
Table 3 Mean (SD) \% BMC measurements

\begin{tabular}{llll}
\hline & \multicolumn{2}{l}{$\%$ BMC } & \\
\cline { 2 - 4 } & Whole body & Lumbar spine & Femoral neck \\
\hline Controls & $100.1(4.6)$ & $100.2(9.3)$ & $100.3(9.7)$ \\
All IBD & $97.0(4.5)^{\star}$ & $96.5(12.7)$ & $93.1(12.0)^{\star}$ \\
Crohn's disease & $96.1(4.5)^{\star}$ & $96.4(12.7)$ & $91.6(10.5)^{\star}$ \\
Ulcerative colitis & $98.9(4.3)$ & $96.5(13.6)$ & $96.0(14.5)$ \\
\hline$\star{ }^{\star}<0.05$ compared with &
\end{tabular}

${ }^{\star} \mathrm{p}<0.05$ compared with controls.

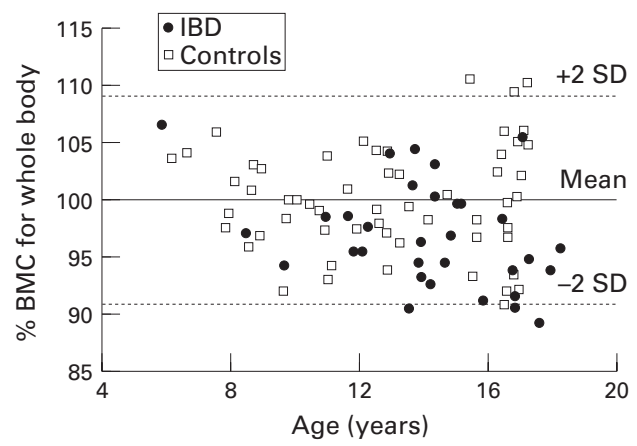

Figure 1 Distribution of \% BMC of the whole body with age. Mean $\pm 2 S D$ based on control data.

allowed definition of a normal reference range for interpretation of \% BMC in the children with IBD (fig 1). \% BMC was reduced for the whole body and the femoral neck in the patient group as a whole when compared with the controls $(p<0.05)$ (table 3 and fig 1). When analysed separately the children with Crohn's disease had significantly lower \% BMC for the whole body and the femoral neck whereas those with ulcerative colitis did not have significantly reduced \% BMC at any site. Of the children with IBD, $41 \%$ had a \% BMC less than $1 \mathrm{SD}$ below the mean for the whole body, $34 \%$ at the lumbar spine and $47 \%$ at the femoral neck.

RELATION TO BONE BIOCHEMISTRY

All biochemical investigations were within normal limits (table 4) and did not suggest the presence of abnormalities of calcium homoeostasis, bone formation, or bone resorption. There was no correlation between the biochemical markers of bone metabolism and \% BMC at any site.

RELATION TO DISEASE ACTIVITY

The mean duration of IBD at the time of the study was 2.9 (range $0.3-10.3$ ) years. The mean (SD) disease score at the time of participation in the study was 3.6 (1.8) and over the preceding year 5.1 (2.5). Other indicators of disease activity including erythrocyte sedimentation rate, platelet count, and haemoglobin concentration were within normal limits. There was no correlation between \% BMC and disease activity at the time of the study or over the preceding year in patients with Crohn's disease or ulcerative colitis whether analysed separately or together.

RELATION TO STEROID USAGE

Six children with IBD had never been treated with steroids. Of those children who received steroid therapy, the mean (SD) duration of treatment was $1.2(1.5)$ years. The mean (SD) steroid score was 6.3 (5.9). The mean (SD) percentage of time since diagnosis spent on steroids was 40.4 (38.3). Twenty children had discontinued steroid treatment before participating in the study and in these the mean (SD) time between discontinuation and participation was 1.3 (1.4) years. There was no correlation between the magnitude of steroid usage and \% BMC nor between percentage time on or time since discontinuing steroids and \% BMC. There was, however, a significant reduction in \% BMC when the children who had received steroids were compared with those who had not and with the control group (ANOVA p<0.005) (fig 2).

\section{Discussion}

To our knowledge, this is the first published study of BMC in childhood IBD. The results indicate that children with IBD have reduced BMC when compared with healthy local control children, even after correction for their short stature and reduced body weight. This reduction in BMC was noted for the whole body and the femoral neck. We have assumed that a reduction of $1 \mathrm{SD}$ from the mean might be expected to be a clinically important change, as this has been shown to increase fracture risk in adults. ${ }^{20}$ We calculated the power of our study to detect this magnitude of change as $99 \%$ for the children with IBD as a whole, $97 \%$ for those with Crohn's disease, and $85 \%$ for those with ulcerative colitis. The reduction in \% BMC was only statistically significant for the subjects with Crohn's disease and not for those with ulcerative colitis. The mean reduction ( $95 \%$ confidence intervals) in $\%$ BMC for the whole body between the children with Crohn's disease and the controls was 4.0 (1.6 to 6.3$)$ and those with ulcerative colitis and the controls was $1.1(-1.9$ to 4.1$)$. By comparison with an SD of 4.6 in the control population, this would indicate that some of the children with Crohn's disease are likely to have a clinically important reduction in \% BMC, whereas those with ulcerative colitis almost certainly do not, despite the small numbers in the study. At the lumbar spine the mean difference between the children with IBD and the controls was $3.8(-0.9$ to 8.4$)$, indicating that no clinically important difference was detected, as well as there being no statistically significant difference.

The cause of the reduced BMC remains unclear. Studies in adults with IBD have produced conflicting results. In some, an association has been found between osteopenia and steroid usage. ${ }^{21} 22$ Other studies have suggested that reduced $\mathrm{BMC}$ is secondary to reduced bone formation ${ }^{23}$ or increased rates of bone loss..$^{25}$ Low bone mineral density has been noted at diagnosis in Crohn's disease, ${ }^{26}$ and growth failure in children with established IBD has been associated with increased disease activity $^{18}{ }^{19}$ and nutritional deficiencies. ${ }^{27}$

This study did not find an association between \% BMC and disease activity. Disease activity is difficult to measure accurately, particularly retrospectively, and our assessment 
Table 4 Biochemical measurements; values are mean (SD)

\begin{tabular}{lll}
\hline & IBD & Normal range \\
\hline Calcium $(\mathrm{mmol} / \mathrm{l})$ & $2.3(0.1)$ & $2.1-2.6$ \\
Phosphate $(\mathrm{mmol} / \mathrm{l})$ & $1.2(2.0)$ & $1.1-1.9$ \\
Alkaline phosphatase $(\mathrm{IU} / \mathrm{l})$ & $178.7(76.4)$ & $120-180$ \\
25-Hydroxycholecalciferol $(\mathrm{ng} / \mathrm{ml})$ & $19.8(10.5)$ & $8.0-50$ \\
Parathyroid hormone $(\mathrm{pmol} / \mathrm{l})$ & $2.4(1.4)$ & $0.9-5.4$ \\
Urine hydroxyproline/creatinine ratio $(\mu \mathrm{mol} / \mathrm{mol})$ & $37.5(20.2)$ & $20-120$
\end{tabular}

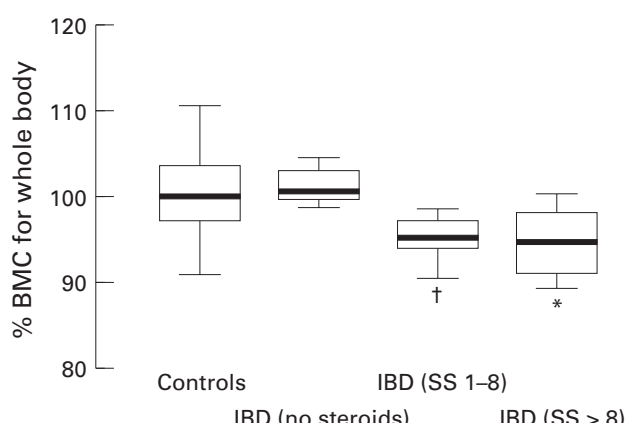

Figure 2 Effect of steroids on \% BMC. SS = steroid score. ${ }^{\star}{ }_{p}<0.05$ compared with controls and IBD (no steroids); $t p<0.05$ compared with controls (ANOVA and Tukey's post hoc multiple comparison test).

may not have been sensitive enough to detect an association. Also, the relatively small numbers in this study may not have been sufficient to reveal an association. In common with others, ${ }^{2829}$ this study demonstrates that the reduction in BMC did not appear to be due to malabsorption of calcium or to metabolic bone disease. However, it is possible that important but transient differences in osteoblast or osteoclast activity may occur during the acute inflammatory process, which may lead to longer term effects on BMC but which were not detected by biochemical measurements undertaken in patients who in this study were mostly in remission from acute inflammatory episodes. The results of this study do not suggest a nutritional basis for the osteopenia, as all measures of body composition were normal.

The role of steroids in the reduction in BMC is unclear. Although children with IBD who received steroid treatment had a lower \% BMC than those who did not and the control group, the difference in \% BMC was not related to the magnitude of steroid use. Steroids are known to have a direct inhibitory effect on osteoblast activity and to have adverse effects on growth hormone action. ${ }^{4}$ It may be that the steroid effect is an all or none effect and therefore not related directly to dosage. Treatment with steroids may also act as a marker for other variables, such as worsening disease activity, which, in combination with steroid treatment, leads to a reduction in bone mineralisation. Studies of other chronic diseases in childhood have produced differing results. Reduced bone mineralisation has been documented in juvenile chronic arthritis and appears to be associated with disease activity rather than steroid usage, ${ }^{30}$ whereas, after renal transplantation in chronic renal failure, steroid treatment has been implicated. ${ }^{31}$ Long term inhaled steroids in childhood asthma have not been shown to adversely affect bone mineral density, ${ }^{32}{ }^{33}$ in contrast with studies in adults. ${ }^{34}$
The finding of osteopenia in children with IBD is important as it may predispose to osteopenia and osteoporosis in later adult life because of a failure to achieve adequate peak bone mass, which is one of the major determinants of future risk of fracture. A reduction in BMC of 1 SD below the mean has been shown in adults to increase future fracture risk by $50-100 \% .^{20}$ Assuming that similar relationships are relevant to the bones of growing children, this finding suggests that a number of children with IBD may be at substantial risk of fractures in later adult life.

We suggest that BMC should be monitored in all children with IBD and that if a significantly reduced BMC is observed, the use of steroids should be avoided if possible.

In conclusion, this study demonstrates that osteopenia occurs relatively frequently in children with IBD particularly those who have received steroids. This may be due to a number of interrelated factors and the underlying mechanism requires further evaluation.

We are grateful to Mr D Coleman, Mr J H Pearce, and Mrs RJ Pettit for assistance with the DXA measurements. J T W is supported by the local oncology charity, Llandough Aims to Treat Children with Cancer and Leukaemia with Hope (LATCH)

1 Clements D, Motley RJ, Evans WD, Harries AD, Rhodes J, Coles RJ, Compston JE. Longitudinal study of cortical bone loss in patients with inflammatory bowel disease. Scand F Gastroenterol 1992;27:1055-60.

2 Fries W, Giacomin D, Plebani M, Martin A. Effect of experimental colitis on bone metabolism in the rat.
Digestion 1994;55:229-33.

3 Slemenda CW, Miller JZ, Hui SL, Reister TK, Johnson CC Jr. Role of physical activity in the development of skeletal Jr. Role of physical activity in the development of ske
mass in children. f Bone Miner Res 1991;6:1227-33.

4 Lukert BP, Raisz LG. Glucocorticoid-induced osteoporosis. Lukert BP, Raisz LG. Glucocorticoid-induced Dis Clin North Am 1994;20:629-50.
Rheum

5 Compston JE. Osteoporosis, corticosteroids and inflammatory bowel disease. Aliment Pharmacol Ther 1995;9:237-50. 6 Shaw NJ, Bishop NJ. Mineral accretion in growing bones: a framework for the future? Arch Dis Child 1995;72:177-9.

7 Hildebrand H, Karlberg J, Kristiansson B. Longitudinal growth in children and adolescents with inflammatory bowel disease. F Pediatr Gastroenterol Nutr 1994;18:165-73. 8 Cowan FJ, Parker DR, Jenkins HR. Osteopenia in Crohn's disease. Arch Dis Child 1995;73:255-6.

9 Freeman JV, Cole TJ, Chinn S, Jones PRM, White EM, Preece MA. Cross sectional stature and weight reference curves for the UK, 1990. Arch Dis Child 1995;73:17-24.

10 Cole TJ, Freeman JV, Preece MA. Body mass index Cole TJ, Freeman JV, Preece MA. Body mass index
reference curves for the UK, 1990. Arch Dis Child 1995;73: $25-9$.

11 Tanner JM. Growth at adolescence. 2nd Ed. Oxford: Blackwell, 1962

12 Brook CGD. Determination of body composition of children from skinfold thickness. Arch Dis Child 1971;46: 182-4.

13 Durnin JVGA, Rahaman MM. The assessment of the amount of fat in the human body from measurements of skinfold thickness. Br $\mathcal{F}$ Nutr 1967;21:681-9.

14 Siri WE. Body composition from fluid spaces and density: analysis of methods. In: Brozek J, Henschel A, eds. Techniques for measuring body composition. Washington DC: National Academy of Science, 1961:223-44.

15 Svendsen OL, Haarbo J, Christiansen C. Accuracy of measurements of body composition by dual energy $x$-ray urements of body composition by dual energy $x$-ray

16 Prentice A, Parsons TJ, Cole TJ. Uncritical use of bone mineral density in absorptiometry may lead to size-related mineral density in absorptiometry may lead to size-related artefacts in the identification of bone
nants. Am $\mathcal{F}$ Clin Nutr 1994;60:837-42.

17 Harvey RF, Bradshaw JM. A simple index of Crohn's disease activity. Lancet 1980;i:514.

8 Truelove SC, Witts LJ. Cortisone in ulcerative colitis: final report on a therapeutic trial. $B M F$ 1955;2:1041-8.

19 Motil KJ, Grand RJ, Davis-Kraft L, Ferlic LL, O'Brian Smith E. Growth failure in children with inflammatory bowel disease: a prospective study. Gastroenterolgy 1993; 105:681-91

20 Gardsell P, Johnell O, Nilsson BE. The predictive value of forearm bone mineral content measurements in men. Bone 1990;11:229-32.

21 Bernstein CN, Seeger LL, Sayre JW, Anton PA, Artinian L, Shanahan F. Decreased bone density in inflammatory bowel disease is related to corticosteroid use and not disease diagnosis. F Bone Miner Res 1995;10:250-6. 
22 Silvennoinen JA, Karttunen TJ, Niemela SE, Manelius JJ, Lehtola JK. A controlled study of bone mineral density in patients with inflammatory bowel disease. Gut 1995;37:716.

23 Abitbol V, Roux C, Chaussade S, et al. Metabolic bone assessment in patients with inflammatory bowel disease. Gastroenterology 1995;108:417-22.

24 Croucher PI, Vedi S, Motley RJ, Garrahan NJ, Stanton MR, Compston JE. Reduced bone formation in patients with osteoporosis associated with inflammatory bowel disease. Osteoporosis International 1993;3:236-41. 25 Motley RJ, Clements D, Evans WD, et al. A four year longibowel disease. Bone Miner 1993;23:95-104.

26 Ghosh S, Cowen S, Hannan WJ, Ferguson A. Low bone mineral density in Crohn's disease, but not in ulcerative colitis, at diagnosis. Gastroenrerology 1994;107:1031-9.

27 Kelts DG, Grand RJ, Shen G, et al. Nutritional basis of growth failure in children and adolescents with Crohn's growth failure in children and adoles.
disease. Gastroenterology 1979;76:720-7.

28 Silvennoinen J. Relationships between vitamin D, parathyroid hormone and bone mineral density in inflammatory bowel disease. F Intern Med 1996;239:131-7.
29 Scharla SH, Minne HW, Lempert UG, et al. Bone mineral density and calcium regulating hormones in patients with inflammatory bowel disease (Crohn's disease and tive colitis). Exp Clin Endocrinol 1994;102(1):44-9.

30 Polito C, Strano CG, Rea L, et al . Reduced bone mineral content and normal serum osteocalcin in non-steroidtreated patients with juvenile rheumatoid arthritis. Ann Rheum Dis 1995;54:193-6.

31 Boot AM, Nauta J, Hokken-Koelega AC, Pols HA, de Ridder MA, de Muinck Keizer-Schrama SM. Renal transplantation and osteoporosis. Arch Dis Child 1995;72:502-6.

32 Martinati LC, Bertoldo F, Gasperi E, Micelli S, Boner AL. Effect on cortical and trabecular bone mass of different anti-inflammatory treatments in preadolescent children with chronic asthma. Am f Respir Crit Care Med 1996;153: 232-6.

33 Kinberg KA, Hopp RJ, Biven RE, Gallagher JC. Bone mineral density in normal and asthmatic children. $\mathcal{F}$ Allergy Clin

34 Reid DM, Nicoll JJ, Smith MA, Higgins B, Tothill P, Nuki $\mathrm{G}$. Corticosteroids and bone mass in asthma: comparison with rheumatoid arthritis and polymyalgia rheumatica. BMF 1986;293:1463-6. 